\title{
GaAs 异质结构材料的电化学研究
}

\author{
陈自姚 䂙永富 彭瑞伍 \\ （中国科学院上海冶金研究所）
}

\section{一、引 言}

目前正在发展的 III-V 族化合物半导体器件如 FET, 激光器和太阳电池等用的材料均要 求多层、异质和 $p-n$ 结等结构, 而常用的 $\mathrm{C}-\mathrm{V}$ 法和 Hall 法不能同时测定这类材料的载流子浓 度, 厚度和 $p-n$ 结位置. 在这方面电化学法已取得一定的成功 ${ }^{[1]}$. 但异质结材料的载流子浓 度分布和 $p-n$ 结位置等测试尚未见报道. 本文以太阳电池材料为典型例子, 研究了它的电化 学行为. 在此基础上讨论了该材料的电学性质, 第一次测得了 $p \mathrm{GaAlAs}-p \mathrm{GaAs}-n \mathrm{GaAs}$ 多层 异质材料的完整结构图. 据此选择和确定的最佳外延结构材料, 已用于制作转换效率较为稳 定的太阳电池.

\section{二、实验方法}

实验装置如图 1 所示. Ga As 样品由探针压置在塑料密封环上, 与浓 $\mathrm{KOH}$ 溶液接触形成 Mott-Schottky 势垒, 接触面积为 $0.025 \mathrm{~cm}^{2}$. 样品的欧姆接触分别在 $p-n$ 两侧形成. 可控阳极 溶解是以样品本身为阳极并在均匀光照下进行的. 电容值在频率为 $100 \mathrm{kc} / \mathrm{s}$, 讯号幅度 $100 \mathrm{mv}$ 和无照开路时测量, 而采样瞬间,样品停止溶解.

\section{三、实 验结 果}

1. $\mathrm{C}^{-2}-\mathrm{V}$ 特性: 图 2 为 $p \mathrm{GaAs} / \mathrm{KOH}$ 和 $n \mathrm{GaAs} / \mathrm{KOH}$ 接触的典型 $\mathrm{C}^{-2}-\mathrm{V}$ 特性. 图中 $p$ 型和 $n$ 型材料为同一样品上 $p-n$ 结两边的 $p$ 型层和 $n$ 型层,其浓度分别为 $1 \times 10^{18}$ 和 $7 \times 10^{17}$ $\mathrm{cm}^{-3}$. 从图 2 可见, 二者的 $\mathrm{C}^{-2}-\mathrm{V}$ 特性均成线性并能符合 Mott-Schottky 方程式:

$$
1 / C_{s c}^{2}=\frac{2}{e \varepsilon \varepsilon_{0} N}\left(u_{s c}-\frac{k T}{e}\right)
$$

式中脚注 $s c$ 为空间电荷区, 其余均为常用符号, 这一关系在半导体电化学中已广泛应用 ${ }^{[2]}$.

按式 (1), 当 $1 / C_{s c}^{2} \approx 0, u_{s c} \approx \frac{k T}{e} \doteq 0$, 也就是图 2 中电容曲线外推可以得出能带平 坦 $\left(u_{s c}=0\right)$ 的电势一平带电势. 虽然我们用的溶液与文献 [3] 不同, 但换算至 $\mathrm{pH}=1$ 时, 图 2 中得出的平带电势对 $n$ 型和 $P$ 型 GaAs 能与文献 [3] 的结果相符. 从图 2 中 $\mathrm{C}^{-2}-\mathrm{V}$ 的走 向和平带电势值可以确定半导体材料的导电类型和载流子浓度. 如果将 $\mathrm{C}^{-2}-\mathrm{V}$ 曲线与阳极溶 解相结合, 利用式 (1) 即可测得 $n \mathrm{GaAs}$ 和 $p \mathrm{GaAs}$ 的载流子浓度分布.

2. I-V 特性: 图 3 为同 $-\mathrm{GaAs}$ 样品中 $\boldsymbol{p}$ 型层和 $n$ 型层在 $\mathrm{KOH}$ 溶液中的典型电流一电

本文 1980 年 9 月 29 日收到. 
压曲线 (已换算为 $\mathrm{pH}=1$ 时的情况). 从图 3 可见,对于 $n$ 型材料, 阳极极化光照时出现极限 电流, 电位超过一定值时, 电流突然增加; 而阴极极化时, 光照和暗时无明显不同, 均随电位增 加而增大. 对于 $p$ 型材料则相反。这些结果与很多文献结果相符 ${ }^{[2]}$.

由此可见, $I-V$ 曲线的走向有助于判别 $G a A s$ 材料的导电类型. 文献中提到可以按 $I-V$ 曲线上的扩散电流和电流突然增加的电势值来估计材料的载流子浓度. 我们认为由于在

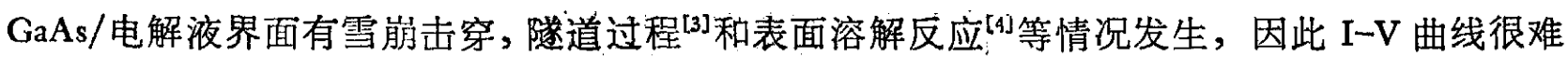
确切反映材料的杂质浓度.

3. 光效应：图 4 表明 $p$ 型材料的阴极过程和 $n$ 型材料的阳极过程分别因光照而增强, 此 时极化电流与光照几乎成正比关系.

图 5 是利用 Mott-Schottky 方程, 阳极溶解和光效应测得的 $p \mathrm{GaAlAs}-p \mathrm{GaAs}-n \mathrm{GaAs}$ 材料 的纵向浓度分布和相应的溶解电流特性图. 从图 $5 \mathrm{a}$ 可见 $p \mathrm{GaAs}$ 层和衬底浓度分别为 $1 \times 10^{18}$ 和 $4 \times 10^{17}$ 时, 能与 Hall 法测得结果相符. 图 $5 \mathrm{~b}$ 表征此样品的 $p$ 型层和 $n$ 型层在所控制的电 位下, 溶解电流与导电类型的关系.从图可见, $p$ 型材料阳极溶解在暗电流下进行, 当溶解接近 $p-n$ 结时, 暗电流分量开始减小, 而光电流逐渐增大, 当进入 $n$ 型层时, 阳极溶解全部由光电流 完成. 这与图 1,3的结果完全一致. 因此根据阳极溶解电流变化也能正确估计 $p-n$ 结的位置.

4. $p \mathrm{GaAlAs}-p \mathrm{GaAs}-n \mathrm{GaAs}$ 材料的特性: GaAs 异质结构太阳电池材料要求: i) 抗反射层 $p$ GaAlAs 具有梯度分布的禁带宽度.' ii) 良好的 GaAs $p-n$ 结特性 ${ }^{[5]}$. 为此根据上述 测得的 电化学行为, 研究了样品的如下特性：i) $\mathrm{Al}$ 含量: 在同一样品上腐蚀相邻 $A 、 B$ 两点, 其深度 分别为 0.2 和 $0.4 \mu \mathrm{m}$, 腐蚀坑直径 $1.8 \mathrm{~m} / \mathrm{m}$. 然后在 $A, B$ 二点上进行电子探针分析, 结果表 明 $A$ 点 $\mathrm{Al}$ 含量较表面为低, 而 $B$ 点检测不到 $\mathrm{Al}$ 的存在. 这一结果是与图 5a 所示的浓度分布 曲线相符的. 因为在图 5a 中, $A$ 点位于 $p \mathrm{GaAlAs}$ 层中, 而 $B$ 点则位于 $p \mathrm{GaAs}$ 层中. ii) 厚度: 根据上述结果估计 $p \mathrm{GaAlAs}$ 层的厚度为 $0.28 \mu \mathrm{m}$ 和 $p \mathrm{GaAs}$ 结深为 $1.5 \mu \mathrm{m}$; 前者曾用扫描电镜 直接测得为 $0.3 \mu \mathrm{m}$, 可见二者大体一致. iii) 载流子浓度分布: 图 5a 中清晰表明多层异质和 $p-n$ 结构中载流子浓度分布, 但是在同样掺杂条件下 $p \mathrm{GaAlAs}$ 层中 $\mathrm{Al}$ 含量的不同可能引起载 流子浓度的变化, 因此图 5a 所示的 $p \mathrm{GaAlAs}$ 层的载流子浓度分布可能反映出组份的分布情况.

图 $5 a$ 和图 6 分别为二种 $p \mathrm{GaAlAs}-p \mathrm{GaAs}-n \mathrm{GaAs}$ 材料的典型特性曲线. 从图可以看出二 者各层中的载流子浓度分布和厚度以及组分分布大致相近, 但两曲线的 $p-n$ 结特性完全不同. 对照电池效率 ${ }^{[2]}$ 可知, 图 $5 a$ 所示特性曲线的材料制得的太阳电池效率一般可以稳定在 $15 \%$ 左 右, 而图 6 所示的材料, 则效率仅为 $5 \sim 7 \%$.

\section{四、结语}

1. 本文用 $1 / \mathrm{C}^{2}-\mathrm{V}, \mathrm{I}-\mathrm{V}$ 和光效应等电化学方法研究了 $p \mathrm{GaAs}-n \mathrm{GaAs}$ 和 $p \mathrm{GaAlAs}-p \mathrm{GaAs}-$ $n \mathrm{GaAs}$ 的电化学行为, 讨论了 $p \mathrm{GaAs}$ 和 $n \mathrm{GaAs}$ 的电极过程, 并第一次用电化学 $\mathrm{C}-\mathrm{V}$ 法测出了 GaAs 异质结构的分布图, 从而估计了材料的导电类型, 载流子浓度, 厚度和大数组分分布等.

2. 借助电子探针, 扫描电镜,霍耳测量和金/半 C-V 法测量, 分别对电化学法测得的各层 的厚度和载流浓度进行了校正, 得出了甚为符合的结果.

3. 用电化学 $C-V$ 法已测得不同类型的 $p \mathrm{GaAlAs}-p \mathrm{GaAs}-n \mathrm{GaAs}$ 曲线. 从这些曲线可以得 知材料的完整结构和判断材料的特性. 已经证明, 用曲线形状较为合理的材料, 可以制得效率 稳定在 $15 \%$ 左右的太阳电池. 


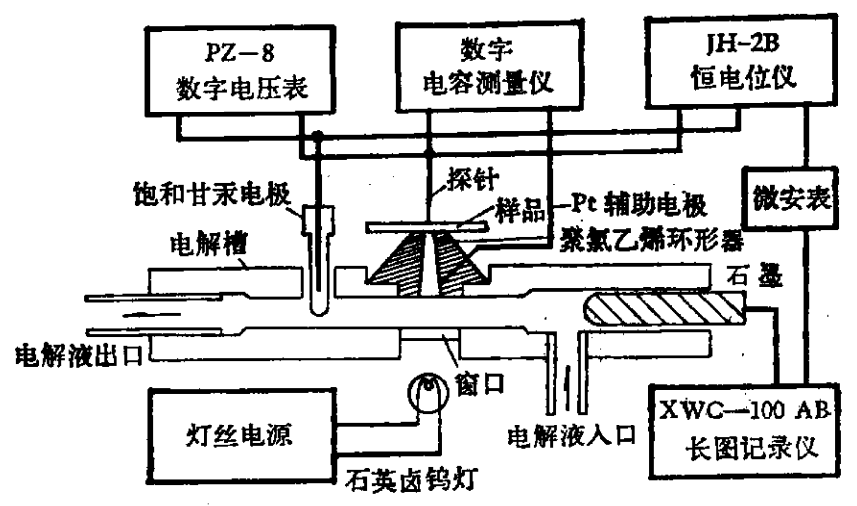

图 1～电化学测量装置示意图

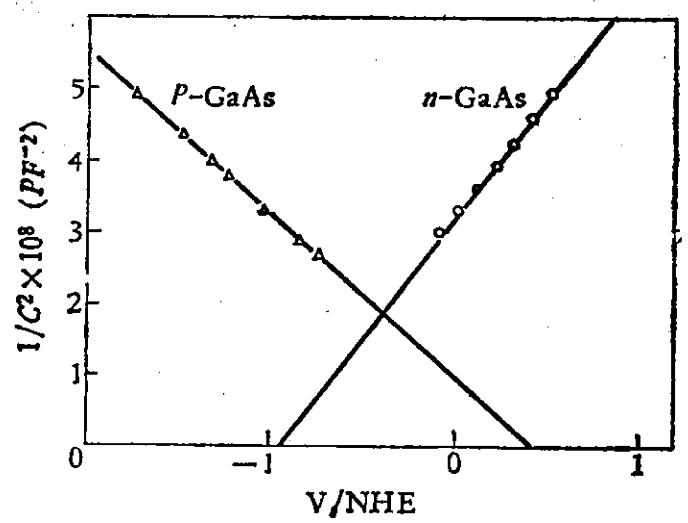

图 2 GaAs 材料的 C-V 特性 $\mathrm{pH}=1$

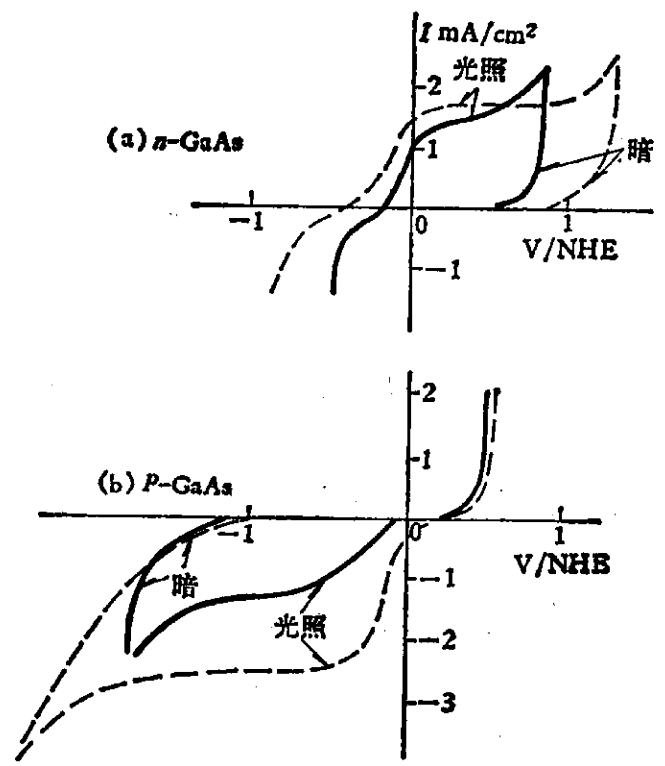

图 3 GaAs 材料的 I-V 特性 $\mathrm{pH}=1$

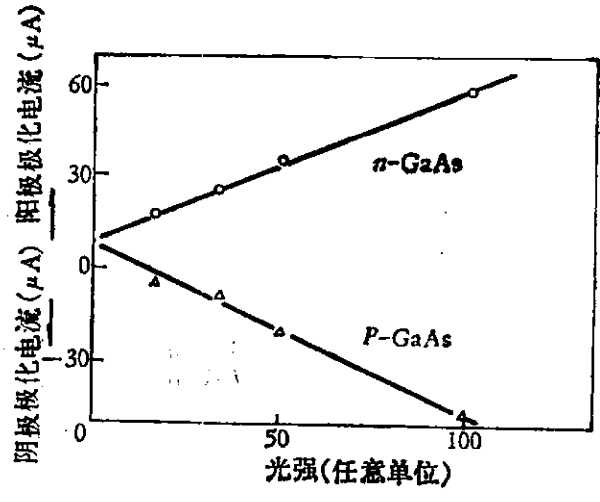

图 4 GaAs 材料的光效应特性曲线

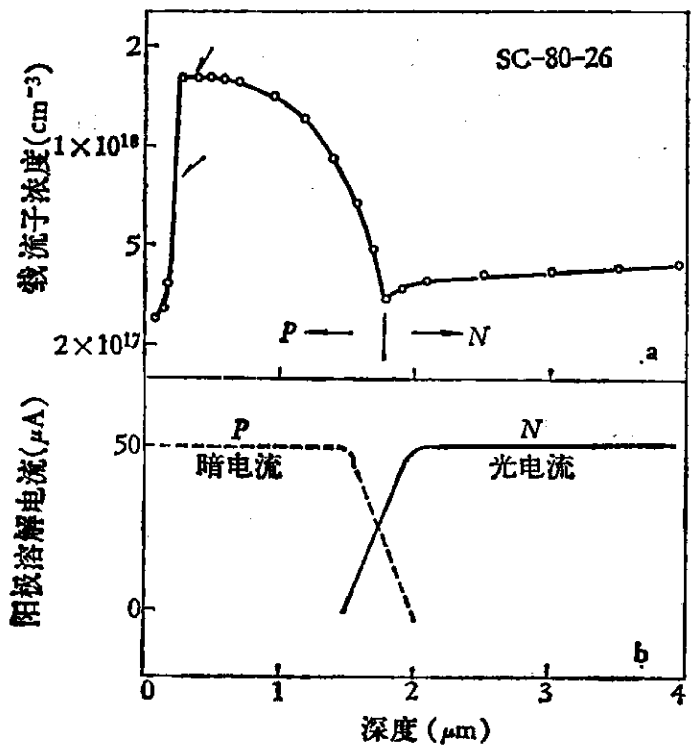

图 $5 \mathrm{GaAs}$ 异质结构材料的纵向浓 度分布和阳极溶解电流曲线

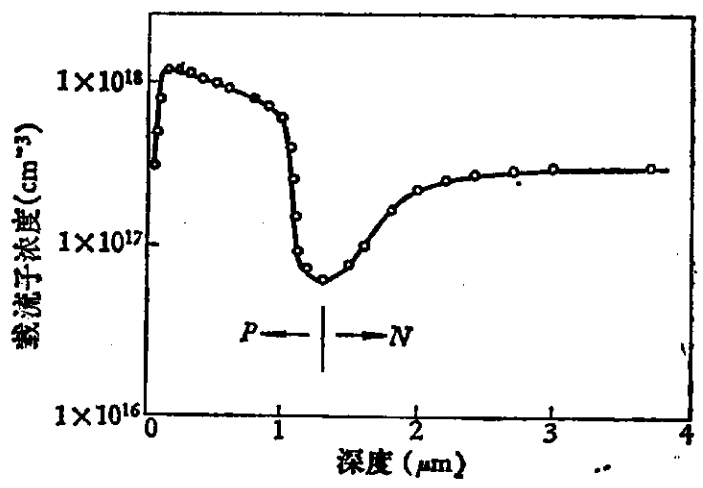

图 6 p GaAlAs-pGaAs-nGaAs 材料的特性

\section{考文献}

[1] Ambridge, T., Stevenson, J. \& Redstall, R. M., J. Electrochem. Soc., 127(1980), 1: 222-227.

[2] Memming, R., in Topic in Surface Chemistry (Eds. Kay, E., Bagus, P. S.), Planum Press, N. Y., 1977, $1-28$.

[ 3 ] Laflere, W. H., Van Meirhaeghe, R. L. \& Cardon, F., Surface Science, 59(1976), 2: 401-412.

[4]丁永庆、彭瑞伍、陆风贞, 科技通讯, 上海冶金研究所, $1979,11$.

[ 5] Charam, S., J. Appl. phys., 50(1979), 2: 963-968. 